\title{
Research and Development of Miniaturized Fuel Evaporation Closed Chamber for Motorcycle
}

\author{
Hong $\mathrm{Bin}^{1, \mathrm{a}}, \mathrm{Zhu} \mathrm{Di}^{1}$ and Wang Hongmei ${ }^{2}$ \\ ${ }^{1}$ Internal Combustion Engine Research Institute of Tianjin University, China \\ ${ }^{2}$ Tianjin Tianbo Science \& Technology Co,.Ltd., China
}

\begin{abstract}
With the increasingly serious environmental pollution, pollution emissions of motorcycles had gradually been concerned in all developed countries. But the fuel evaporative emissions had not attracted sufficient attention and its test equipment was far from perfect. Thus, this paper addressed the miniaturized problems of closed chamber. On the basis of analyzing fuel evaporative emission regulations and the features of closed room, technical solutions are determined and a prototype was successfully developed. The paper successfully resolved the seal problem and innovatively developed the pressure balance system and the temperature and humidity regulation system. After experimental verification, the prototype had reliable performance and stable operation. And it met the requirements of the relevant standards and it was also equivalent to imported equipments. Thus, this paper successfully resolved the miniaturized problems of closed chamber.
\end{abstract}

\section{Introduction}

With the increasingly serious environmental pollution, pollution emissions of motorcycles have gradually been concerned in all developed countries, and more stringent emissions regulations for motorcycles have been promulgated. There are three major sources of emissions: emissions, crankcase blow-by gas and fuel evaporation. Among them, the exhaust emissions and crankcase blowby gas have caused concern of motorcycle manufacturers and the appropriate control measures have been taken. But the fuel evaporative emissions have not attracted sufficient attention. Currently, in the world, only a few countries and regions implement the fuel evaporative emission regulations for motorcycles, and China also too.

However, the associated test equipment is far from perfect. Currently, internationally accepted fuel evaporative emission measurement methods for motorcycles are collection method and airtight chamber method. The test equipment of collection method is relatively simple, but has the poor inaccurate, poor reproducibility and poor consistency. Closed chamber method, currently the mainstream testing method, has the accurate data, good repeatability, but sophisticated equipment and high cost. Existing closed chambers, mainly for automobile, have too large volume and too high price to Purchase for gasoline Engine Manufacturer (more than 200 million Yuan per set). Therefore, in accordance with national standards and indicators gasoline engine requirements, the paper studied the miniaturized problems of the fuel evaporation closed chamber, and developed the equipment in line with national standards, suitable for motorcycle and gasoline engine.

\footnotetext{
${ }^{\mathrm{a}}$ Corresponding author: tianbohb@126.com
}

\section{Hardware Structure}

Hardware Structure of the closed chamber consisted of $\mathrm{HC}$ detector, pressure balance system, temperature/humidity regulation system, wind circulation system and sealing system. The Hardware Structure of the Closed Chamber is shown as Figure 1.

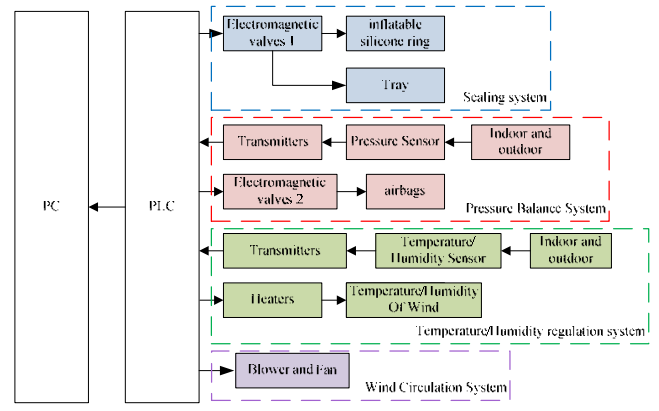

Figure 1. Hardware Structure of the Closed Chamber

\section{System Components}

\subsection{HC Detector}

Selecting the operating range of detector is so important that you can get the best resolution in measurement, calibration, leak detection and other processes. Hydrocarbon analyzer frequency of twice per minute automatic recording of data processing systems, and can be kept permanently. Analyzer automatically records the 
testing data with twice per minute, and permanently saves data.

\subsection{Pressure Balance System}

The closed chamber is completely sealed in the process of testing. When the ambient temperature changes indoor, the barometric pressure will change as the temperature varies. In order to simulate the real situation, the test must be done under constant pressure, and standard differential pressure within $\pm 500 \mathrm{~Pa}$ between indoor pressure and atmospheric pressure. Therefore, we used a pressure balance system (shown as Figure 2) to control the balance of pressure caused by temperature changes.

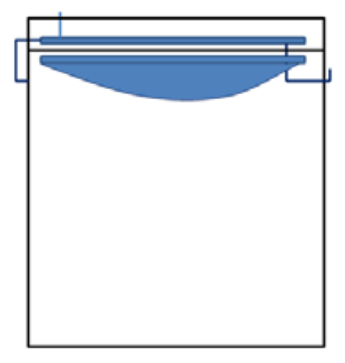

Temperature Decreased

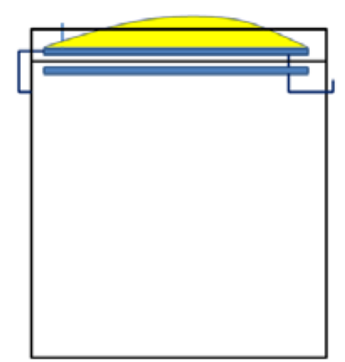

Temperature Rised
Figure 2. Changes of the Airbags

When the indoor temperature decreases in the process of testing, the outdoor air goes into the indoor airbags via a control valve, and the net volume of sealed chamber decreases. Thus, the indoor pressure is kept correspondence with the outdoor pressure. When the indoor temperature rises, the indoor air goes into the outdoor airbags via another control valve and the net volume of sealed chamber increases. Thus, the indoor pressure is also kept correspondence with the outdoor pressure. In the process of testing, the difference of indoor and outdoor pressure must be controlled within $\pm 200 \mathrm{~Pa}$. Pressure recording system automatically records and shows the pressure data with twice per minute, and permanently saves data. And it automatically calculates and displays the pressure difference $\Delta \mathrm{p}$, too. The accuracy of the pressure recording system is within $\pm 5 \mathrm{~Pa}$ and its resolution is $\pm 1 \mathrm{~Pa}$.

\subsection{Temperature/Humidity Regulation System}

The Closed chamber is equipped with temperature and humidity regulation system in order to achieve control of the ambient temperature and humidity in the process of testing. The system uses PID intelligent control system. Its deviation is $\pm 3{ }^{\circ} \mathrm{C}$, better than the standard required by $5^{\circ} \mathrm{C}$. The system automatically records and shows the temperature data and humidity data. The accuracy of the temperature/humidity regulation system is within $\pm 1.0^{\circ} \mathrm{C}$ and its resolution is $\pm 0.1{ }^{\circ} \mathrm{C}$.

The system uses intelligent PID control that is combined the intelligent control and conventional PID control. It is adaptive and parameters of its controller online change. The system does not rely on accurate mathematical model so that it has good adaptability, strong anti-interference ability and robustness. Its block diagram is shown as Figure 3.

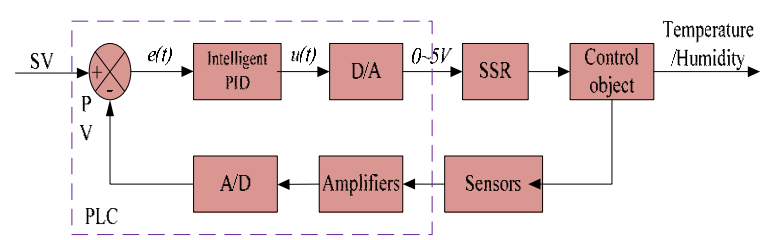

Figure 3. Schematic of PID Control

In practice, the control law adopts the sectional PID control scheme. When the deviation of the actual temperature and the set temperature is large, system will heat or cool at a large rate. When approaching a thermostat, it don't cause oscillation because of too much inertia to reduce the transition time.

\subsection{Wind Circulation System}

To fully mixing the indoor atmosphere to ensure uniform temperature and $\mathrm{HC}$ concentration, wind circulation system is configured. The air flow generated is unable to face trial motorcycle. When you open the door, interior $\mathrm{HC}$ concentration can be reduced to the environment level. Large air fan is installed in the exhaust port. The indoor gas is replaced again every 16 seconds. Before and after the test, $\mathrm{HC}$ concentration can quickly reduce to the $\mathrm{HC}$ concentration level of the environment. Five mixing fans are equipped in the closed chamber and the range of their air volume is $10.8-14 \mathrm{~m}^{3} / \mathrm{min}$. The system is capable of sufficiently mixing the indoor gas to ensure indoor temperature and $\mathrm{HC}$ concentrations homogeneous.

\subsection{Sealing System}

Seal is an important parameter of the closed chamber, but it also is a technical difficulty. If the seal is poor, it will directly affect the measurement accuracy. Standard provides: the leakage rate must be less than $4 \%$ within four hours. In order to ensure its seal, 316 stainless steel was used as the inner wall, the interface was welded, and the punched holes were fully welded. Tray is installed under air vents. When the tray rises and close air vents, ring on the tray is pressed. Ring has a certain flexibility and generates a certain deformation to ensure the seal when the tray is closed.

Door of the closed chamber often open, so inflatable silicone ring was used as sealing structure. In the natural state, the ring hides in $\mathrm{U}$ groove structure. When inflated, the ring outward bulge because of internal pressure to impinge on the door frame so that the seal is ensured.
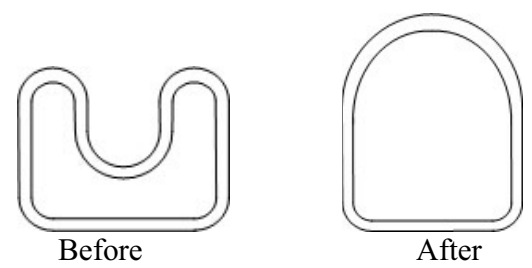

Figure 4. Cross Section of Sealing Ring 
When installed, the sealing ring is placed in $U$ grooves of door and its concave outward. Its inlet was connected with air compressor via fast access. When used, the control valve opened and compressed air gone into the cavity of the inflatable ring after the sealed chamber door was closed. Pressure of the cavity increased so that the concave of the inflatable ring expanded outwardly to form arc-shaped. Therefore, the arc and the door frame obtained an interference fitting and its seal had good effect.

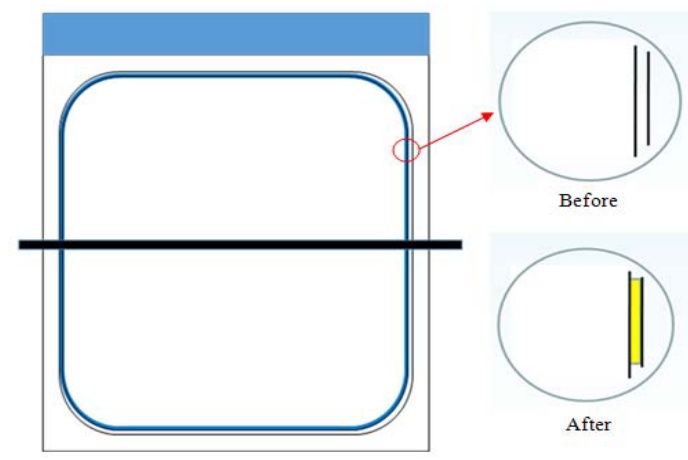

Figure 5. Schematic of Sealing Method

\section{Software}

The system uses WINDOWS operating systems, and uses industrial control computers and programmable control system as a control center. The system has good manmachine interface and digital control mode. Test interface can display real-time data, such as indoor and outdoor temperature, fuel temperature, steam temperature, indoor and outdoor pressure. The main interface is shown as Figure 6.

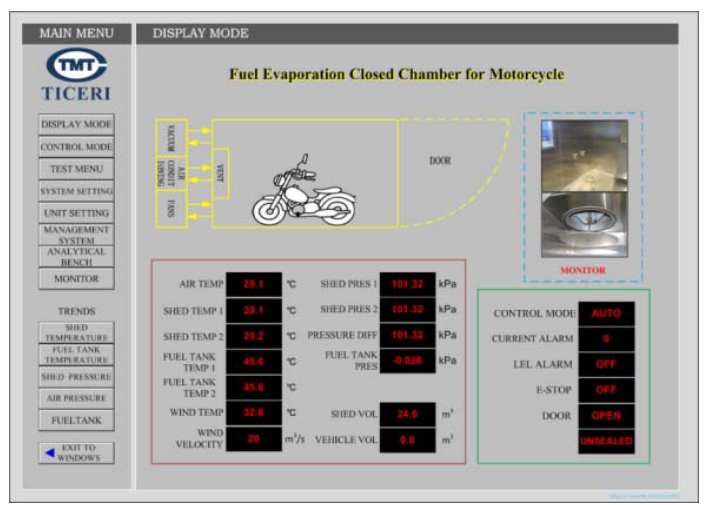

Figure 6. the Main Interface

\section{Results and Analysis}

In order to verify the seal of the closed chamber, uniformity and seal experiment were done in accordance with national standards GB/T 20998. The experimental curve is shown as Figure 7.

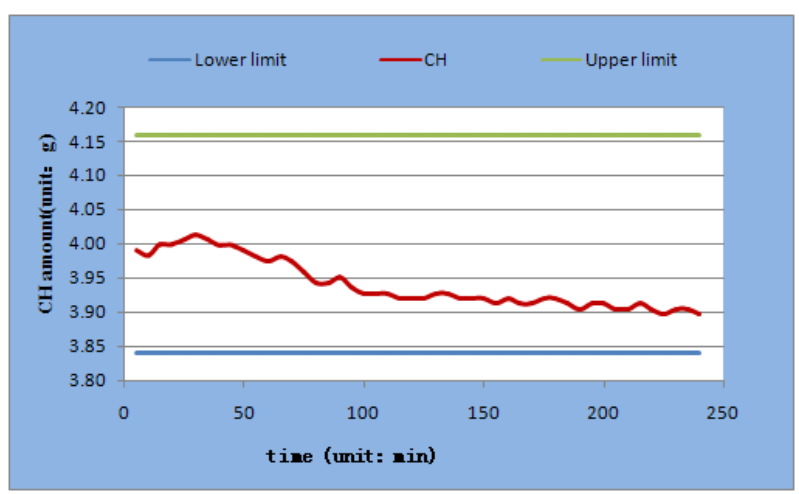

Figure 7. the Curve of $\mathrm{CH}$ Amount

From the above chart shows: before the experiment beginning, $4.0 \mathrm{~g}$ hydrocarbons were injected into the closed chamber via sampling port and mixed for 5 minutes. Test Result shown: HC amount is $3.98 \mathrm{~g}$ and its deviation is $-0.5 \%$. The deviation is in the range of national standards GB/T 20998 requirements $( \pm 2 \%)$ and it proofed that indoor $\mathrm{HC}$ concentration is uniform. After 4 hours (240min), HC amount is $3.90 \mathrm{~g}$ and its deviation is $-2.5 \%$ and less than $\pm 4 \%$ (required by national standards GB/T 20998). It also proofed that the seal of the closed chamber is very good.

In addition, this equipment was compared with similar imported equipments. The pressure deviation of the equipment is $\pm 50 \mathrm{~Pa}$. The actual fuel heating curve fluctuated around the theoretical curve and its deviation was controlled in $\pm 0.5^{\circ} \mathrm{C}$. The equipment met the requirements of the relevant standards and also equivalent to imported equipments. Comparative results were shown as Figure 8 to Figure 10.

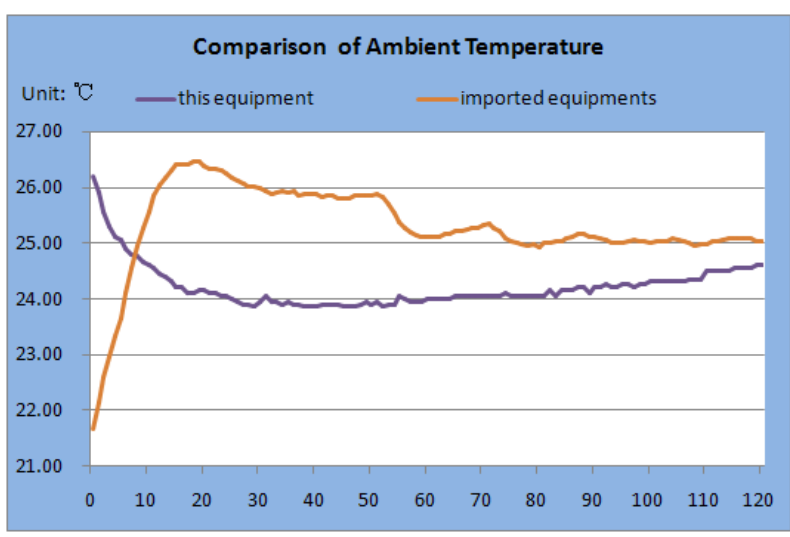

Figure 8. Comparison of Ambient Temperature 


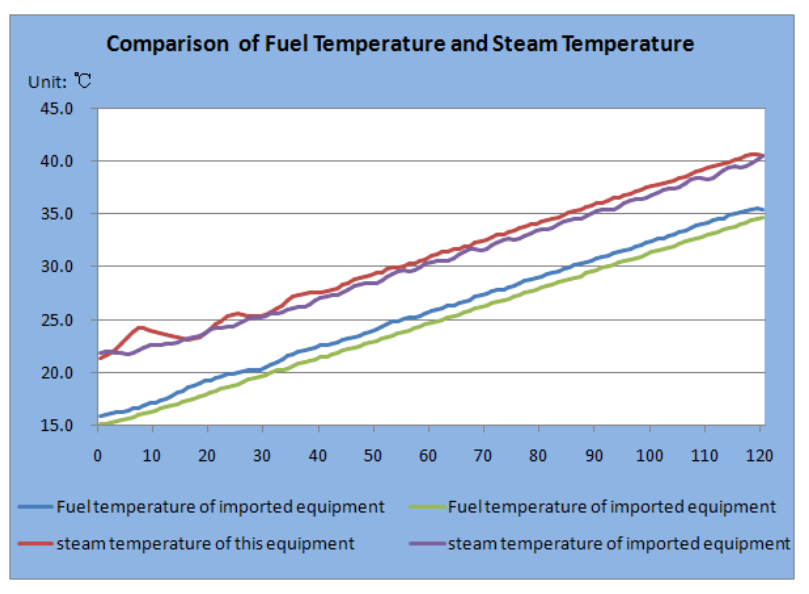

Figure 10. Comparison of Fuel Temperature and Steam Temperature

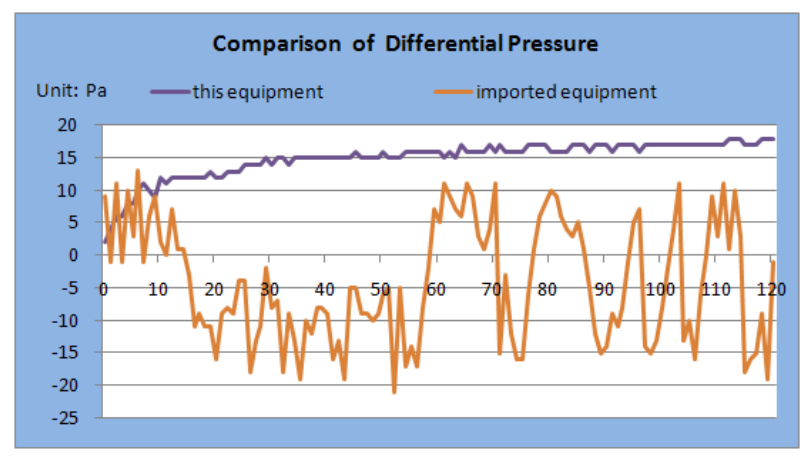

Figure 9. Comparison of Differential Pressure

\section{Conclusion}

This project addressed the miniaturized problems of closed chamber. On the basis of analyzing fuel evaporative emission regulations and the features of closed room, technical solutions are determined and a prototype was successfully developed. Experimental results shown: the miniaturization closed chamber had reliable performance and stable operation. Experimental comparative data shown: the equipment met the requirements of the relevant standards and it was also equivalent to imported equipments. Thus, this equipment greatly reduced the cost and resolved the miniaturized problems of closed chamber.

\section{References}

1. Miao Lei. Study on fuel evaporative emission property of motor vehicles [D]. Tianjin University, 2010.

2. Cheng Shili. Experimental research of the fuel evaporative control system for motorcycles[D]. Tsinghua University, 2012.

3. Jia Quanli. A brief introduction to the test method for fuel evaporative emission of motorcycle(II) $[\mathrm{J}]$. Motorcycle Technology, 2009, 11:38-41.

4. Qiu Jie. Quality of fuel evaporative controlling system of motorcycle and study on related problem[J]. Motorcycle Technology, 2007, 5:16-19

5. GB20998-2007, Limits and measurement methods for evaporative pollutants from motorcycles and mopeds [S].

6. Small Off-Road Engine and Equipment Evaporative Emission Test Procedure, California Environmental Protection Agency, Air Resources Board, El Monte, CA, 2004.

7. Test Procedure for Determining Diurnal Evaporative Emissions from Small Off-Road Engines and Equipment, California Environmental Protection Agency, Air Resources Board, El Monte, CA, 2004.

8. Xie Jianguang. A Study of an Evaporation Emissions Control System for a Vehicle with Petrol Engine[J]. Small internal combustion engine, 2000, 29(4): 3034.

9. Tan Linbo, Liu Shengji, Lu Cunhao, Wang Jian. CFD analysis and experiment research of non-road gasoline engine cooling system[J]. Journal of Chinese Agricultural Mechanization, 2014, 35(1): 189-192.

10. Delia D'Agostino, Paolo Maria Congedo, Rosella Cataldo. Computational fluid dynamics (CFD) modeling of microclimate for salts crystallization control and artworks conservation[J]. Journal of Cultural Heritage . 2013

11. G. Tong, D.M. Christopher, B. Li. Numerical modelling of temperature variations in a Chinese solar greenhouse $[\mathrm{J}]$. Computers and Electronics in Agriculture . 2009 (1) 